Review Article

\title{
Biomechanical, Topological and Chemical Features That Influence the Implant Success of an Urogynecological Mesh: A Review
}

\author{
Carmelo De Maria, ${ }^{1}$ Vito Santoro, ${ }^{1}$ and Giovanni Vozzi ${ }^{1,2}$ \\ ${ }^{1}$ Research Center "E. Piaggio", University of Pisa, Largo Lucio Lazzarino 2, 56122 Pisa, Italy \\ ${ }^{2}$ Dipartimento di Ingegneria dell'Informazione, University of Pisa, Largo Lucio Lazzarino 2, 56122 Pisa, Italy \\ Correspondence should be addressed to Giovanni Vozzi; g.vozzi@centropiaggio.unipi.it
}

Received 17 January 2016; Revised 5 April 2016; Accepted 18 April 2016

Academic Editor: Nihal Apaydin

Copyright ( 2016 Carmelo De Maria et al. This is an open access article distributed under the Creative Commons Attribution License, which permits unrestricted use, distribution, and reproduction in any medium, provided the original work is properly cited.

\begin{abstract}
Synthetic meshes are normally used to treat several diseases in the field of urogynecological surgery. Not-optimal selection of mesh and/or its not-correct implant may increase patient's pain and discomfort. The knowledge of mechanical behaviour and topological and chemical properties of a mesh plays a fundamental role to minimize patient's suffering and maximize the implant success. We analysed several papers reporting the meshes application for urogynecological pathologies, to extrapolate the principal parameters that normally are used to characterise the biomechanical, topological, and chemical properties, and to verify their influence on implant success. In this way we want demonstrate that, knowing these features, it is possible to foresee the success of a mesh implant. This review shows that the application of a mesh strictly depends on elastic modulus, failure load, porosity and pore size, filament diameter, polymer weight, and crystallinity. To increase the success of the implant and to help choice of optimal mesh for a clinical need, two indexes have been proposed for comparing, in an easier way, the mechanical performance of different commercially available meshes.
\end{abstract}

\section{Introduction}

Nowadays, polypropylene (PP) synthetic meshes are commonly used in many urogynecological surgical procedures, such as sacrocolpopexy, anterior-posterior pelvic organ prolapse (POP), and suburethral sling for urinary incontinence treatment.

POP is one of major problems that occur in more than $50 \%$ of women after childbirth and it may be treated [1] with several surgical procedures. Nevertheless, further postsurgical prolapse or recurrences are observed due to the increase of average life expectancy. The longevity determines a progressive deterioration of type I collagen, which is gradually replaced by less resistant type III collagen. Several studies reveal that the pelvic organ prolapse is either caused by excessive pressure within endopelvic fascia or fascial disruptions that require appropriate in situ reinforcements [2]. Normally the fascia takes about 3 months to recover $70 \%$ of its natural resistance [3]. The main goals of prosthetic surgery are the complete reconstruction of pelvic floor, the restoration of normal anatomy and function, the absence of tension on the vaginal wall (cause of pain) and of complications (e.g., infection or allergic reactions), and a high degree of satisfaction by patients.

The implant of biocompatible synthetic meshes significantly improves the restoration of anatomy of anterior vaginal wall. However, a high rate of complications, including $10 \%$ erosion, is a matter of concern. In addition, significant changes into pelvic wall structure can be evaluated by palpating the surface of the vaginal epithelium that appears rigid. Generally, the implant sites have low elongation capacity and flexibility which can lead to pain, discomfort, and dyspareunia in human body: these indications mean that prosthesis is not completely compatible in terms of mechanical properties of natural tissue [4]. 


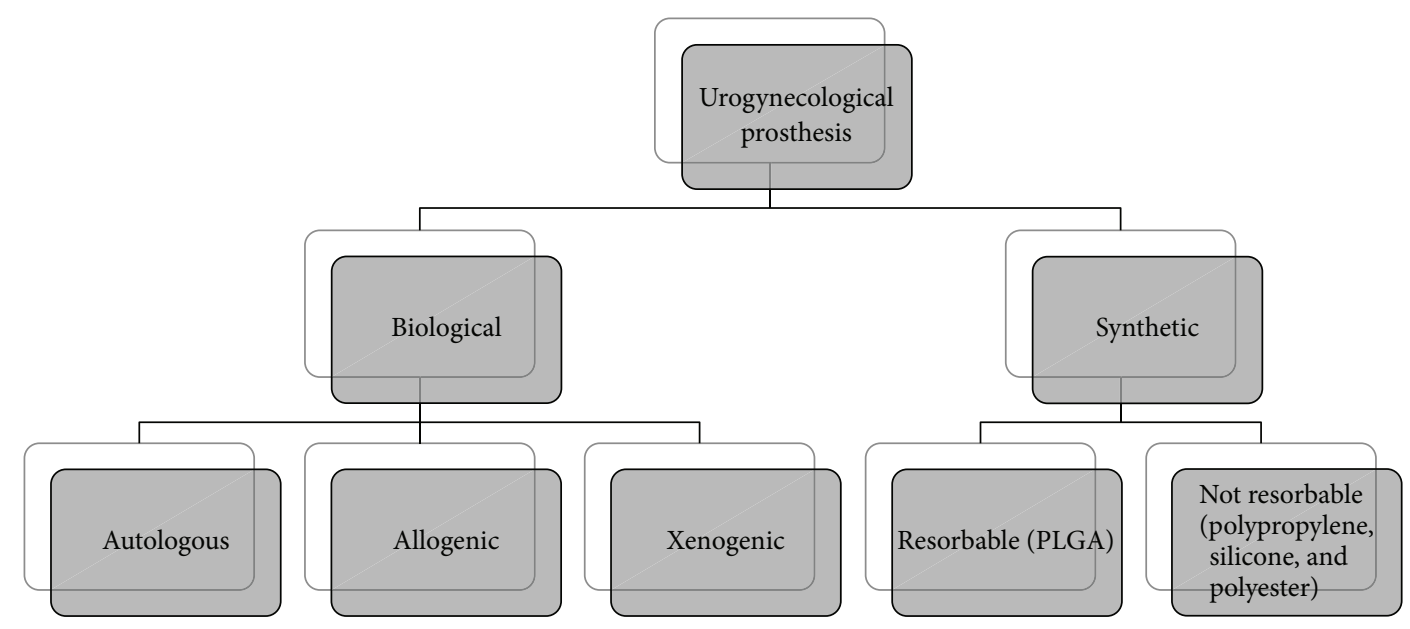

FIGURE 1: Classification of urogynecological prosthesis.

Benson et al. [5] show that the surgical technique concerning the use of meshes has better outcomes within apical vaginal prolapse compared to vaginal surgery with a sacrospinous fixation. A large amount of papers support the use of mesh in surgery; in particular, the guidelines for vaginal prolapse surgery show that meshes are better performing with respect to other traditional techniques [6]. In comparison to old techniques the innovative surgical procedure for transvaginal prolapse (Apogee, Perigee, and Prolift) has shown good results in short term, despite having significant complications such as buttock pain, vaginal erosion, erosion of the bladder, and infection and therefore should be used carefully. Some of these consequences could be related also to the surgical procedure, such as the mesh preloading; in other cases, the intraoperative retraction of the mesh could be misinterpreted as shrinkage [7].

Nevertheless, the use of polymeric meshes presents best results in terms of permanence and success of reconstructive procedures that currently have a failure rate greater than $30 \%$ using the traditional methods [8]. This high failure rate is due to the fragility of endogenous tissue in female patients with prolapse as reported in several reports $[9,10]$. A good biomechanical integration of mesh with the pelvic tissue is the fundamental property that any prosthesis used in urogynecology and andrology should have. As well-known from literature, a rigid material can develop an excessive stress at the interface inducing prosthesis erosion and tissue exposure [11]. Parameters such as mesh size, regrowth inside its fabrics, its mechanical, chemical, and physical properties, and anchoring technique play an important role on the success of a prosthetic implant [12]. The mechanical properties should be comparable to that of natural tissue, and meshes should be stable for a long time showing resistance to shrinkage. Pore size highly influences the success of implant; a pore size greater than $75 \mu \mathrm{m}$ encourages regrowth of blood vessels, fibroblast colonization, and collagen production [13].

Therefore, several complications are closely related to mesh features such as topology, porosity, stiffness, and filament composition.
A wide range of meshes is currently available to clinicians for urogynecological and andrological surgery. Generally, it is possible to classify the products on the basis of the biomaterial used (Figure 1). Biological prostheses have the theoretical advantage of reducing the tissue erosion rate but in the same time they present several disadvantages such as mechanical inconsistency and potential transmission of infections. Furthermore, autologous implants require presurgical procedure into patients increasing their suffering. This last problem is overcome by allografts prosthesis where tissues are harvested from cadavers and biomechanically tested before their use, but often it is difficult to find donors or the explanted tissue has no right features for the implantation. Xenografts are easily available even if different studies show the presence of an excessive inflammatory reaction which can lead to rejection process. Acellular xenogeneic collagen matrix transplants, used to repair advanced prolapse, have not produced the desired results considering the high rate of failure due to postsurgical procedures complications [14]. Then, to overcome the limits and problems due to prosthesis produced by natural tissues, several meshes made of absorbable polymers have been tested but their inefficiency for urogynecological implants has been demonstrated [15]; cells colonize these structure and start to restore the damaged tissue with a reduced inflammatory response, but their degradation time is less than of that of tissue restoration, so their support is not sufficient to ultimate the recovery of natural tissue. For these reasons, the nonresorbable synthetic meshes are considered ideal for reconstructive surgery of the pelvic tissues.

Unfortunately, the newly formed tissue is often atrophic and without vascular network, causing poor tissues regeneration with risks of inadequate healing and mesh exposure.

Several studies present in the literature show that in vivo dimensional changes of mesh are the main cause of stiffness increase and low restore of vaginal tissues standard properties [4]. None of commercially available materials satisfies all the requirements [16, 17]. Nylon, Marlex, and Gore-Tex meshes have higher erosion rates, higher stiffness, and also 
TABle 1: Percentage of principal complications reported in the literature.

\begin{tabular}{lcc}
\hline Complications & $\begin{array}{c}\text { Range based on } \\
\text { clinical data (\%) }\end{array}$ & $\begin{array}{c}\text { Range based on } \\
\text { random trials (\%) }\end{array}$ \\
\hline $\begin{array}{l}\text { Erosion } \\
\text { Pelvic, groin, and } \\
\text { buttocks pain }\end{array}$ & $1-18.8$ & $5-19$ \\
$\begin{array}{l}\text { Dyspareunia } \\
\text { New surgical }\end{array}$ & $2.9-18.3$ & $0-10$ \\
intervention & $2.2-15$ & $8-27.8$ \\
\hline
\end{tabular}

substantial differences in pore size, in manufacturing process, in surface properties, and in mesh topology [7] compared to PP meshes currently marketed. For these reasons PP mesh is considered the gold standard for urogynecological treatment.

The PP meshes erosion rate in surgery for stress incontinence is around $1-3 \%$ [18]. Synthetic meshes made of other polymers have a low elasticity, normally with pore size less than $10 \mu \mathrm{m}$ and multifilament weft. These features may predispose the patient to erosion and pain (17-20\%) [19, 20]. From this point of view, PP meshes appear to have better characteristics of resistance and elasticity, but their values do not match those of surrounding tissues and in situ integration could be affected by this difference $[21,22]$.

The problems associated with the surgical use of mesh for pelvic organ prolapse vary drastically from small erosions to perforations in bladder and intestines. The list of complications includes acute and chronic infections, tissue contraction due to mesh shrinkage, erosion of tissue adjacent to the mesh, pain, and dyspareunia, and limitation of sexual activity [2326]. In Table 1, the literature data are reported.

Summarising, the type of material that composes the meshes and their biomechanical and topological features, plays an important role in the tissue regeneration process and consequently in the implant success, as highlighted by the present review. In addition, we propose the use of two indexes for classifying commercial available meshes, for indicating possible design direction, and for helping the surgeons in their choice on the basis of their clinical needs to maximize the implant success.

\section{Biomechanical Properties of Commercial Urogynecological Mesh}

The optimal biomechanical properties that prosthesis for urogynecological surgery should present $[27,28]$ are not well defined yet. The mechanical behaviour of these meshes depends on the polymer in which they are made as well as on the type of fiber used, their weft, and pore size [4]. Stiffness, relative elongation, and failure load are the principal parameters that characterise the biomechanical behaviour of a mesh. In particular, the mesh stiffness is the factor closely linked to tissue erosion, mesh exposure, and pain. It depends on many factors such as mass per unit area, weft structure, working technique used to fabricate the mesh, and pore size [12].

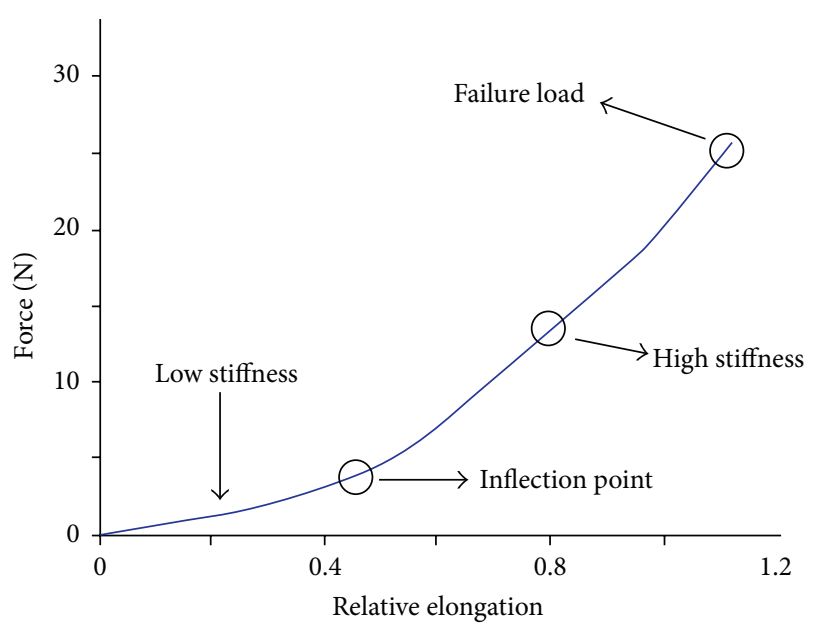

FIGURE 2: Typical force: relative elongation graph of a synthetic mesh.

In the literature different types of slings for incontinence, which have similar weights but fully different biomechanical behaviour and thus different functionality, are reported $[16,29]$. Biomechanical behaviour of meshes is commonly evaluated using uniaxial test, assessed on sterile samples cut in strips. The strip length is bigger than width in order to minimize the effects of nonlinearity. This is due to the clamps of mechanical testing system [4-12]. Before mechanical assessment, each sample is dipped in a physiological solution bath at $37^{\circ} \mathrm{C}$ for 10 minutes and then the mechanical test is performed in wet conditions. On the sample a preload of $0.1 \mathrm{~N}$ is applied. The displacement rate is set up to $50 \mathrm{~mm} / \mathrm{min}$ until the probe is broken. The acquired data allows to determine the stress-strain curve in which distinguishing two different regions is possible: the initial one with a low stiffness due to stretching of mesh weft and a second region with a high stiffness due to polymer mesh (Figure 2) [12]. The low and high stiffness regions are defined as the minimum slope over a $15 \%$ and $30 \%$ relative elongation, respectively. The inflection point is defined as the intercept of the two tangents of stressstrain curve in the two previous regions. Within high stiffness region the registered loads overcome the forces that normally act in physiological conditions (in situ) [4], which are more similar to those present in low stiffness area.

In Table 2 the mechanical properties of several commercially available meshes are reported: Caldera Ascend mesh has the highest value between low and high stiffness region.

These data could be difficult to be understood by surgeons: it is important to determine an index that can be easily read. Furthermore, biological tissues present an anisotropic behaviour, which should be taken into account in the prosthesis design. In the field of hernia repair, the anisotropy index $\lambda$ was proposed $[30,31]$ to describe the different mechanical behaviour along the two different tensile directions in the mesh plane. It is defined as

$$
\lambda=\left|\log \frac{E_{L}}{E_{T}}\right|,
$$


TABLE 2: Mechanical features of principal commercially available urogynecological meshes.

\begin{tabular}{|c|c|c|c|c|}
\hline Mesh & Low stiffness $(\mathrm{N} / \mathrm{mm})$ & High stiffness $(\mathrm{N} / \mathrm{mm})$ & $\begin{array}{l}\text { Relative elongation at } \\
\text { inflection point }(\%)\end{array}$ & Load at mesh failure $(\mathrm{N})$ \\
\hline AMS IntePro Lite ${ }^{\mathrm{TM}}$ & $0.071 \pm 0.01$ & $0.934 \pm 0.04$ & $33.9 \pm 1.0$ & $27.2 \pm 1.9$ \\
\hline Boston Scientific Polyform ${ }^{\mathrm{TM}}$ & $0.13 \pm 0.01$ & $1.42 \pm 0.11$ & $39.9 \pm 1.5$ & $53.8 \pm 4.8$ \\
\hline Caldera Ascend ${ }^{\mathrm{TM}}$ & $0.724 \pm 0.2$ & $1.66 \pm 0.26$ & $13.4 \pm 2.1$ & $41.1 \pm 5.3$ \\
\hline Coloplast NovaSilk $^{\mathrm{TM}}$ & $0.072 \pm 0.05$ & $0.508 \pm 0.09$ & $44.6 \pm 7.5$ & $19.6 \pm 4.5$ \\
\hline Gynecare Gynemesh PS ${ }^{\mathrm{TM}}$ & $0.286 \pm 0.02$ & $1.37 \pm 0.09$ & $25 \pm 0.89$ & $46.3 \pm 2.6$ \\
\hline Mpathy Smartmesh ${ }^{\mathrm{TM}}$ & $0.178 \pm 0.03$ & $0.592 \pm 0.04$ & $29.2 \pm 1.0$ & $22.7 \pm 1.9$ \\
\hline Dipromed DAL3P & $0.32 \pm 0.05$ & $1.18 \pm 0.07$ & $30 \pm 2.5$ & $60 \pm 3.1$ \\
\hline Dipromed EV3P & $0.529 \pm 0.023$ & $0.7535 \pm 0.3$ & $80 \pm 5.0$ & $76.2 \pm 5.2$ \\
\hline Dipromed $120 \mathrm{ML}$ & $0.36 \pm 0.03$ & $0.588 \pm 0.09$ & $80 \pm 5.0$ & $89.6 \pm 4.3$ \\
\hline
\end{tabular}

where $E_{L}$ and $E_{T}$ are the elastic modulus in longitudinal and transverse direction, respectively. Once the mechanical properties have been quantified in two directions, this index allows to compare the mesh behaviour with the target tissue.

The forces that meshes are able to support, reported in Table 2, depend directly on their structural elasticity and are essential for the stability of the implant. Also this parameter is directly related to mesh and tissue erosion, mesh exposure, and pain [12].

For this reason it is important also to determine its failure load and relative elongation at inflection point. Dietz et al. showed [16] that mechanical properties of urogynecological implants should be related to the range of human physiological strength.

For the abdominal wall meshes, the security index $K$ has been defined [30] to evaluate if a mesh is able to support the forces that are generated in situ; it is defined as

$$
K=\frac{\sigma_{m}}{\sigma_{\text {tissue }}},
$$

where $\sigma_{m}$ is the maximum stress which can be sustained by the surgical meshes and $\sigma_{\text {tissue }}$ is the typical stress of the specific tissue. In the case of urogynecological meshes, as precautionary, the same stress used for abdominal wall could be considered [31].

Table 3 shows the security index of different commercial meshes. The bigger the index the less the probability that the mesh is broken by forces acting normally on natural tissue.

Once implanted the mesh must hold its shape and position and must resist different stresses. These can be either raised during surgical procedure or during the patient life. Meshes should present a high stability in an environment with a $\mathrm{pH}$ close to $7.0, \mathrm{PO}_{2}$ less than $40 \mathrm{mmHg}$, and temperature between 28 and $37^{\circ} \mathrm{C}$ [32]. A variation of tensile strength of mesh and an increase of its elongation may cause recurrences.

The long term stability of PP has been tested in several works: experimental results indicate a degradation of PP, with consequent reduction of mechanical resistance [30, 33, 34]. The chemical structure of PP had multiple functional groups that were potential sites for chemical reactions. The carboncarbon backbone was not well shielded since the hydrogen and methyl groups did not pack tightly together.
TABLE 3: Security index of principal commercially available urogynecological meshes (rounded by defect to eliminate the effect of uncertainty).

\begin{tabular}{lc}
\hline Mesh & Security index $K$ \\
\hline AMS IntePro Lite & 2.3 \\
Boston Scientific Polyform & 4.6 \\
Caldera Ascend & 3.5 \\
Coloplast NovaSilk & 1.4 \\
Gynecare Gynemesh PS & TM \\
Mpathy Smartmesh & 4.0 \\
Dipromed DAL3P & 1.9 \\
Dipromed EV3P & 5.2 \\
Dipromed 120 ML & 6.6 \\
\hline
\end{tabular}

\section{Topological Parameters of Commercial Urogynecological Mesh}

Filament diameter, pore size, and porosity play a fundamental role in the development and treatment of complications related to the use of synthetic meshes.

The filament, usually made in PP known also with its commercial name of Prolene ${ }^{\circledR}$ or Marlex ${ }^{\circledR}$ [35], has a diameter which varies within the range of $0.08 \mathrm{~mm}$ to $0.66 \mathrm{~mm}$. This geometrical feature contributes to the formation of fibrotic tissue and tissue integration of mesh, as well as to the success implant, especially in the case of vaginal prolapse [36]. The ideal products for urogynecological surgery are made of monofilament fibers and with large pore size $(>75 \mu \mathrm{m})$ which allow low rates of infection and erosion. This pore size enables the passage of macrophages, fibroblast colonization, a rapid regrowth of blood vessels (angiogenesis), and collagen production. The inflammatory response is stopped quickly by allowing the mesh to be incorporated by fibrous tissue, preventing the granuloma formation. Granuloma develops around the single fibers of mesh as a result of foreign body reaction and can lead to infection, erosion, and inflammation of the tissue in contact with it $[4,36]$. If the mesh has pores smaller than $800 \mathrm{~nm}$, the possibility of granuloma development is higher and it encapsulates synthetic structure, creating a planar scar and reducing inherent flexibility [29-36]. 
TABLE 4: Topological features of principal commercially available urogynecological meshes.

\begin{tabular}{lcc}
\hline Mesh & $\begin{array}{c}\text { Mean diameter of } \\
\text { filament }(\mu \mathrm{m})\end{array}$ & Porosity (\%) \\
\hline AMS IntePro Lite & 0.248 & $66.9 \pm 0.96$ \\
Boston Scientific Polyform & 0.66 & $56.09 \pm 3.2$ \\
Caldera Ascend & 0.248 & $51.3 \pm 4.4$ \\
Coloplast NovaSilk & 0.09 & $61.3 \pm 3.8$ \\
Gynecare Gynemesh PS & 0.094 & $62.1 \pm 3.2$ \\
Mpathy Smartmesh & 0.08 & $71.9 \pm 1.4$ \\
Dipromed DAL3P & 0.12 & $80.4 \pm 2.2$ \\
Dipromed EV3P & 0.12 & $88.0 \pm 1.3$ \\
Dipromed 120 ML & 0.12 & $90.0 \pm 1.5$ \\
\hline
\end{tabular}

The porosity and the mean filament diameter of different meshes (evaluated processing optical and SEM microscopy images) are reported in Table 4 [4-12]. There parameters vary over a wide range.

\section{Chemical Parameters of Commercial Urogynecological Mesh}

In general, considering the weight of commercial products, it is possible to distinguish in two types of mesh: heavy and light meshes [37]. This weight depends on the used polymer and on the weft $[36,38]$. The heavy meshes are usually made with a thick filament, presenting small pore size and high tensile strength. Usually the weight of these meshes is about $100 \mathrm{mg} / \mathrm{mm}^{2}$. The light mesh is usually made of thin filament and it presents large pores. These last meshes have an average weight of $33 \mathrm{mg} / \mathrm{mm}^{2}$, are elastic, and generate a lower foreign body reaction.

As reported in the literature, there is a strong positive correlation between the weight of the mesh and its tensile strength: lighter meshes support lower loads at the failure point [4]. However, tensile strength and elongation have magnitudes higher than those observed in vivo, for this reason the principle of less foreign material in the body is followed.

Finally, the polymer crystallinity increases also the strength as well as the stiffness of relative mesh. Table 5 reports both weight and polymer crystallinity degree of commercial available meshes discussed in this review.

\section{Conclusions}

In this review the principal parameters that influence the success of a mesh implant for the cure of pathologies in urogynecological field have been analysed. We observed that the meshes normally used in this surgical area are made of synthetic polymers, principally PP, and that the tissue response and the damage repair can be related to mechanical properties (as elastic modulus, elongation, and failure load), filament diameter, porosity, polymer molecular weight, and crystallinity.
TABLE 5: Chemical features of principal commercially available urogynecological meshes.

\begin{tabular}{lcc}
\hline Mesh & Weight $\left(\mathrm{mg} / \mathrm{mm}^{2}\right)$ & Crystallinity $(\%)$ \\
\hline Aris & 0.065 & 44.2 \\
Autosuture & 0.083 & 54.4 \\
Avaulta & 0.058 & 47.0 \\
TVTO & 0.093 & 49.1 \\
Uretex & 0.078 & 51.2 \\
Dipromed DAL3P & 0.063 & 47.4 \\
Dipromed EV3P & 0.050 & 47.4 \\
Dipromed 120 ML & 0.039 & 47.4 \\
\hline
\end{tabular}

It is often difficult for a clinician choosing the best mesh for specific clinical needs; for this reason we have proposed two indexes (anisotropy index and security index) that allow to easily classify the mechanical performance of commercially available meshes and furnish a novel methodological approach to analyse their performance.

\section{Competing Interests}

The authors declare that there are no competing interests regarding the publication of this paper.

\section{References}

[1] C. Maher, B. Feiner, K. Baessler, and C. M. Glazener, "Surgical management of pelvic organ prolapse in women. Cochrane Database of Systematic Reviews," International Urogynecology Journal, vol. 22, no. 11, pp. 1445-1457, 2011.

[2] M. A. Hodroff, A. H. Stolpen, M. A. Denson, L. Bolinger, and K. J. Kreder, "Dynamic magnetic resonance imaging of the female pelvis: the relationship with the pelvic organ prolapse quantification staging system," The Journal of Urology, vol. 167, no. 3, pp. 1353-1355, 2002.

[3] P. Saxena and P. Pathak, "Mesh in gynaecological surgery," AOGD Bulletin, vol. 12, no. 2, pp. 25-27, 2012.

[4] K. A. Jones, A. Feola, L. Meyn, S. D. Abramowitch, and P. A. Moalli, "Tensile properties of commonly used prolapse meshes," International Urogynecology Journal and Pelvic Floor Dysfunction, vol. 20, no. 7, pp. 847-853, 2009.

[5] J. T. Benson, V. Lucente, and E. McClellan, "Vaginal versus abdominal reconstructive surgery for the treatment of pelvic support defects: a prospective randomized study with longterm outcome evaluation," American Journal of Obstetrics and Gynecology, vol. 175, no. 6, pp. 1418-1422, 1996.

[6] K. Kapur and V. Dalal, "Mesh repair of vaginal wall prolapse," Medical Journal Armed Forces India, vol. 70, no. 2, pp. 105-110, 2014.

[7] K. Svabík, A. Martan, J. Masata, R. El-Haddad, P. Hubka, and M. Pavlikova, "Ultrasound appearances after mesh implantationevidence of mesh contraction or folding?" International Urogynecology Journal, vol. 22, no. 5, pp. 529-533, 2011.

[8] J. S. Jameson, Y. W. Chia, M. A. Kamm, C. T. M. Speakman, Y. H. Chye, and M. M. Henry, "Effect of age, sex and parity on anorectal function," British Journal of Surgery, vol. 81, no. 11, pp. 1689-1692, 1994. 
[9] C. C. G. Chen, B. Ridgeway, and M. F. R. Paraiso, "Biologic grafts and synthetic meshes in pelvic reconstructive surgery," Clinical Obstetrics and Gynecology, vol. 50, no. 2, pp. 383-411, 2007.

[10] C. D. Dora, D. S. Dimarco, M. E. Zobitz, and D. S. Elliott, "Time dependent variations in biomechanical properties of cadaveric fascia, porcine dermis, porcine small intestine submucosa, polypropylene mesh and autologous fascia in the rabbit model: implications for sling surgery," The Journal of Urology, vol. 171, no. 5, pp. 1970-1973, 2004.

[11] P. Wriggers, Computational Contact Mechanics, Springer, New York, NY, USA, 2nd edition, 2006.

[12] J. P. Shepherd, A. J. Feola, S. D. Abramowitch, and P. A. Moalli, "Uniaxial biomechanical properties of seven different vaginally implanted meshes for pelvic organ prolapse," International Urogynecology Journal and Pelvic Floor Dysfunction, vol. 23, no. 5, pp. 613-620, 2012.

[13] J. L. Brun, L. Bordenaeve, and F. Lefebvere, "Physical and biological characteristics of the main biomaterials used in pelvic surgery," Bio-Medical Materials and Engineering, vol. 2, no. 4, pp. 202-235, 1992.

[14] M. Cosson, P. Debodinance, M. Boukerrou et al., "Mechanical properties of synthetic implants used in the repair of prolapse and urinary incontinence in women: which is the ideal material?" International Urogynecology Journal and Pelvic Floor Dysfunction, vol. 14, no. 3, pp. 169-178, 2003.

[15] H. N. Shah and G. H. Badlani, "Mesh complications in female pelvic floor reconstructive surgery and their management: a systematic review," Indian Journal of Urology, vol. 28, no. 2, pp. 129-153, 2012.

[16] H. P. Dietz, P. Vancaillie, M. Svehla, W. Walsh, A. B. Steensma, and T. G. Vancaillie, "Mechanical properties of urogynecologic implant materials," International Urogynecology Journal and Pelvic Floor Dysfunction, vol. 14, no. 4, pp. 239-243, 2003.

[17] D. E. Fenner, "New surgical mesh," Clinical Obstetrics and Gynecology, vol. 43, pp. 647-652, 2000.

[18] P. E. Petros, "Repairing damage fascia: ongoing and post operative consideration," in The Female Pelvic Floor, P. E. Petros, Ed., pp. 108-156, Springer, Berlin, Germany, 2007.

[19] M. Abdel-Fattah, K. Sivanesan, I. Ramsay, S. Pringle, and S. Bjornsson, "How common are tape erosions? A comparison of two versions of the transobturator tension-free vaginal tape procedure," BJU International, vol. 98, no. 3, pp. 594-598, 2006.

[20] A. L. Siegel, M. Kim, M. Goldstein, S. Levey, and P. Ilbeigi, "High incidence of vaginal mesh extrusion using the intravaginal slingplasty sling," Journal of Urology, vol. 174, no. 4, pp. 13081311, 2005.

[21] A. L. Siegel, "Vaginal mesh extrusion associated with use of Mentor transobturator sling," Urology, vol. 66, no. 5, pp. 995999, 2005.

[22] C. V. Comiter and P. M. Colegrove, "High rate of vaginal extrusion of silicone-coated polyester sling," Urology, vol. 63, no. 6, pp. 1066-1070, 2004.

[23] J. S. Afonso, P. A. L. S. Martins, M. J. B. C. Girao et al., "Mechanical properties of polypropylene mesh used in pelvic floor repair," International Urogynecology Journal and Pelvic Floor Dysfunction, vol. 19, no. 3, pp. 375-380, 2008.

[24] M. E. Falagas, S. Velakoulis, C. Iavazzo, and S. Athanasiou, "Mesh-related infections after pelvic organ prolapse repair surgery," European Journal of Obstetrics Gynecology and Reproductive Biology, vol. 134, no. 2, pp. 147-156, 2007.
[25] R. U. Margulies, C. Lewicky-Gaupp, D. E. Fenner, E. J. McGuire, J. Q. Clemens, and J. O. L. DeLancey, "Complications requiring reoperation following vaginal mesh kit procedures for prolapse," American Journal of Obstetrics and Gynecology, vol. 199, no. 6, pp. 678.e1-678.e4, 2008.

[26] A. Feola, S. Pal, P. Moalli, S. Maiti, and S. Abramowitch, "Varying degrees of nonlinear mechanical behavior arising from geometric differences of urogynecological meshes," Journal of Biomechanics, vol. 47, no. 11, pp. 2584-2589, 2014.

[27] G. W. Davila, H. Drutz, and J. Deprest, "Clinical implications of the biology of grafts: conclusions of the 2005 IUGA Grafts Roundtable," International Urogynecology Journal and Pelvic Floor Dysfunction, vol. 17, supplement 1, pp. S51-S55, 2006.

[28] W. A. Silva and M. M. Karram, "Scientific basis for use of grafts during vaginal reconstructive procedures," Current Opinion in Obstetrics and Gynecology, vol. 17, no. 5, pp. 519-529, 2005.

[29] P. A. Moalli, N. Papas, S. Menefee, M. Albo, L. Meyn, and S. D. Abramowitch, "Tensile properties of five commonly used midurethral slings relative to the TVT," International Urogynecology Journal and Pelvic Floor Dysfunction, vol. 19, no. 5, pp. 655-663, 2008.

[30] E. R. Saberski, S. B. Orenstein, and Y. W. Novitsky, "Anisotropic evaluation of synthetic surgical meshes," Hernia, vol. 15, no. 1, pp. 47-52, 2011.

[31] C. De Maria, S. Burchielli, C. Salvadori et al., "The influence of mesh topology in the abdominal wall repair process," Journal of Biomedical Materials Research-Part B: Applied Biomaterials, 2015.

[32] A. Gomelsky and R. R. Dmochowski, "Biocompatibility assessment of synthetic sling materials for female stress urinary incontinence," Journal of Urology, vol. 178, no. 4, part 1, pp. 11711181, 2007.

[33] D. R. Ostergard, "Degradation, infection and heat effects on polypropylene mesh for pelvic implantation: what was known and when it was known," International Urogynecology Journal and Pelvic Floor Dysfunction, vol. 22, no. 7, pp. 771-774, 2011.

[34] C. R. Costello, S. L. Bachman, S. A. Grant, D. S. Cleveland, T. S. Loy, and B. J. Ramshaw, "Characterization of heavyweight and lightweight polypropylene prosthetic mesh explants from a single patient," Surgical Innovation, vol. 14, no. 3, pp. 168-176, 2007.

[35] P. K. Amid, "Classification of biomaterials and their related complications in abdominal wall hernia surgery," Hernia, vol. 1, no. 2, pp. 70-70, 1997.

[36] C. N. Brown and J. G. Finch, "Which mesh for hernia repair?" The Annals of The Royal College of Surgeons of England, vol. 92, no. 4, pp. 272-278, 2010.

[37] J. S. Afonso, R. M. N. Jorge, P. S. Martins et al., "Structural and thermal properties of polypropylene mesh used in treatment of stress urinary incontinence," Acta of Bioengineering and Biomechanics, vol. 11, no. 3, pp. 27-33, 2009.

[38] L. Procter, E. E. Falco, J. P. Fisher, and J. S. Roth, "Abdominal wall hernias and biomaterials," in Bioengineering Research of Chronic Wounds, A. Gefen, Ed., pp. 425-447, Springer, Berlin, Germany, 1st edition, 2009. 


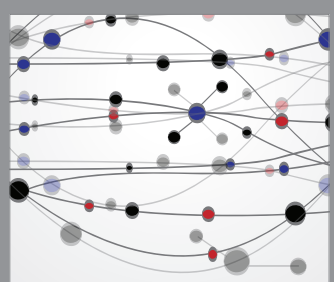

The Scientific World Journal
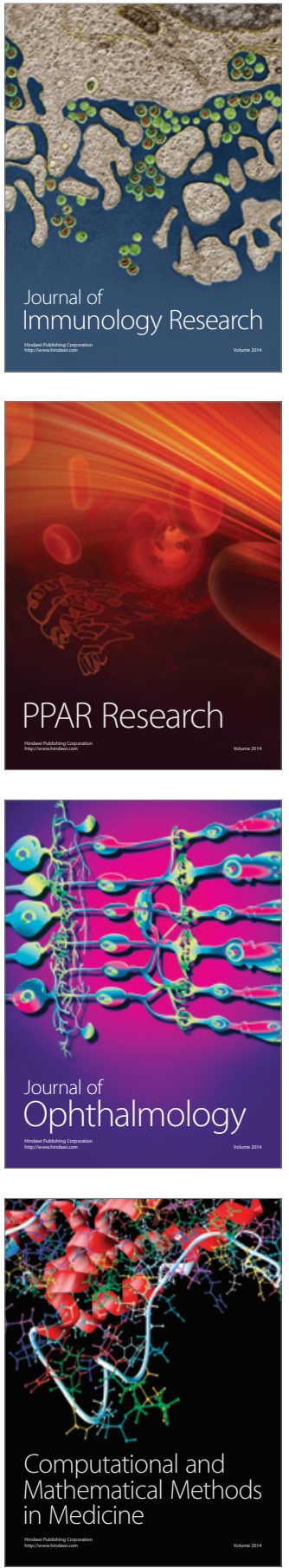

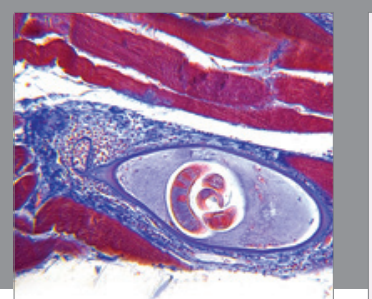

Gastroenterology Research and Practice

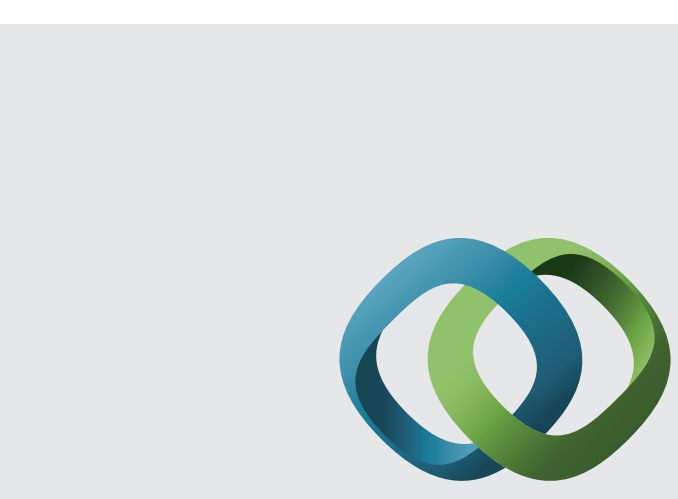

\section{Hindawi}

Submit your manuscripts at

http://www.hindawi.com
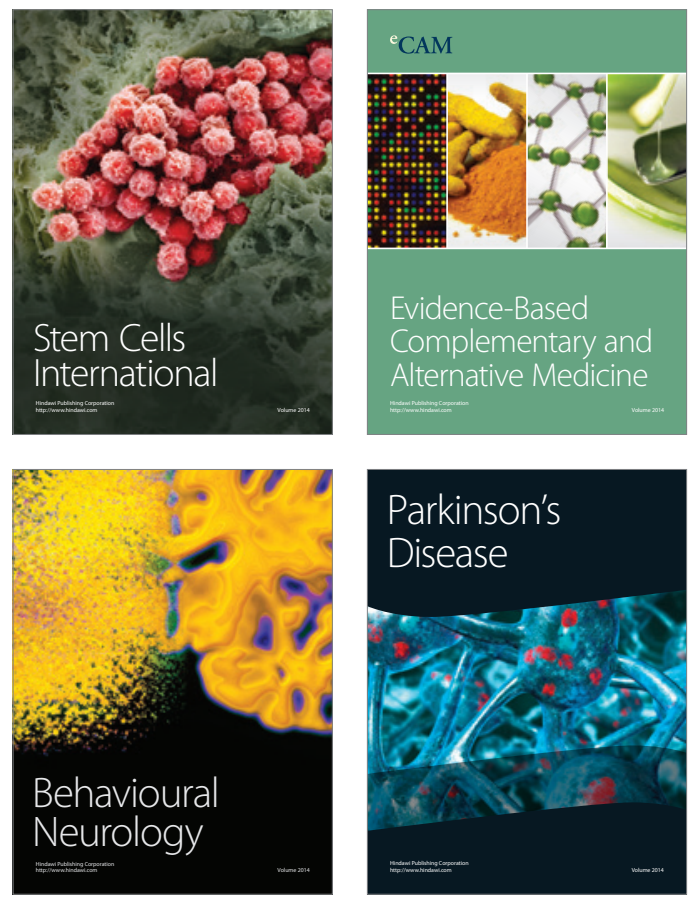
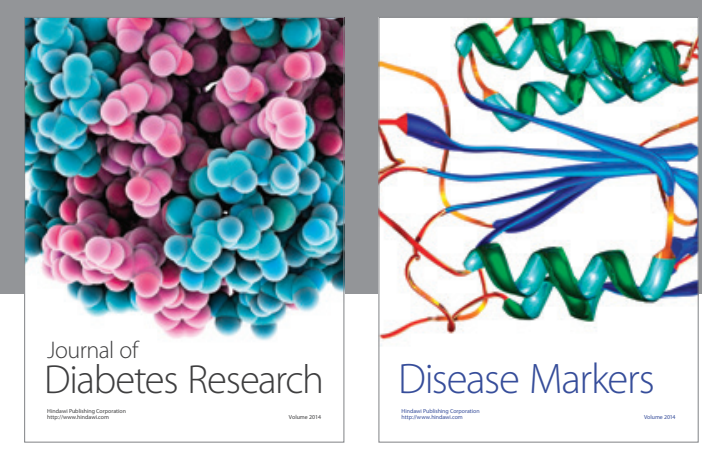

Disease Markers
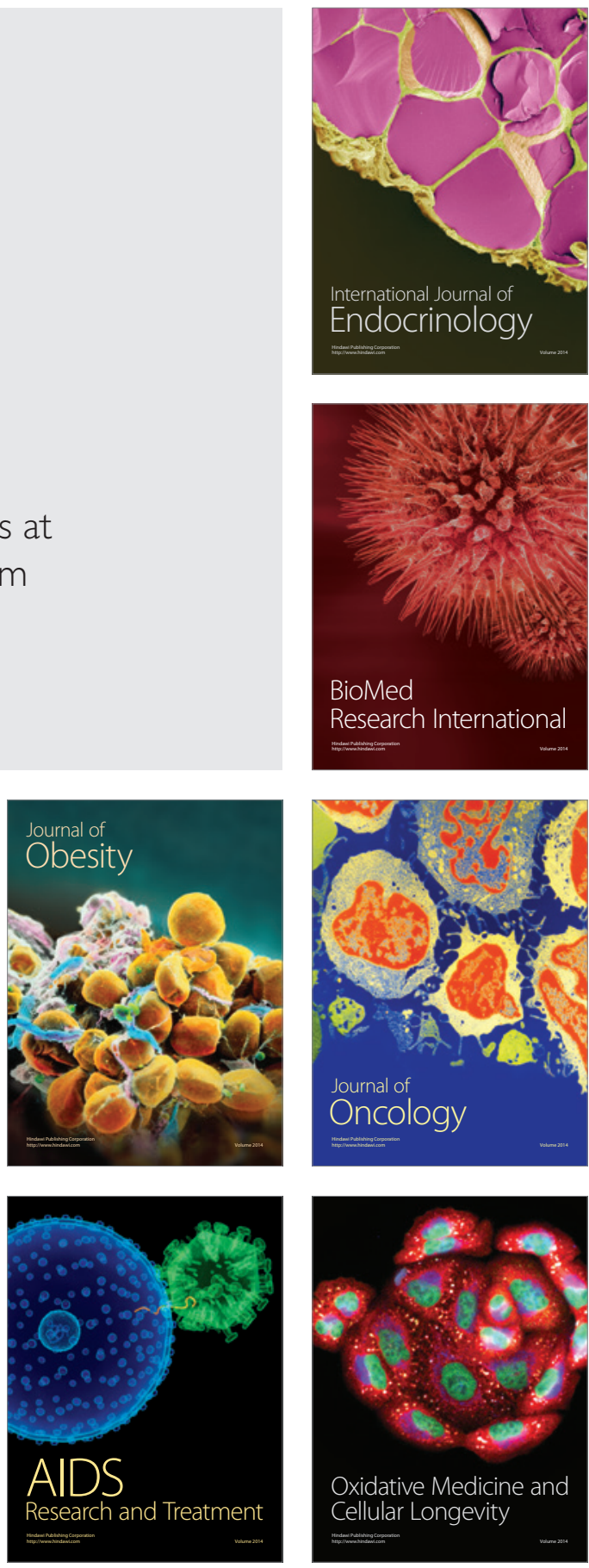